\title{
Harmonic Scalpel in Superficial Parotidectomies; Our Experience at a Tertiary Care Centre
}

\author{
Dr. Omar Mohammad Shafi ${ }^{1}$, Prof. Rauf Ahmad ${ }^{2}$
}

\begin{abstract}
Aims and Objectives: To compare operative time, intra operative and postoperative blood loss, length of hospital stay and post-operative pain between harmonic scalpel and conventional groups. Materials and Method : This study was conducted at Department of Otorhinolaryngology, Head and Neck Surgery of Government Medical College, Srinagar from 2013 to 2015.Patients undergoing superficial parotidectomies $(n=30)$ were included in this study. Results: Harmonic scalpel proved better in all aspects for superficial parotidectomiesas compared to conventional method. Average intraoperative blood loss in superficial parotidectomy patients was significantly less for harmonic group $(37.9 \mathrm{ml})$ than conventional group $(49.1 \mathrm{ml})$, $p$ value $<05$. Furthermore, average hospital stay for superficial parotidectomy patients was significantly shorter in Harmonic group (1.22 days) than in Conventional group (1.77days), with a p value <.05.Average postoperative pain in patients undergoing superficial parotidectomies less in Harmonic group than conventional group but statistically significant only at 24 HRS. Conclusion: Use of Harmonic Scalpel is recommended in superficial parotidectomies.
\end{abstract}

Keywords: Harmonic scalpel, superficial parotidectomies, Blood loss, operative time, Hospital stay

\section{Introduction}

In the endeavour for advancement of surgical methods the introduction of harmonic Scalpel provides an exciting opportunity.Ultrasonic shear technology has long been used for various surgical procedures, such as laparoscopic cholecystectomy ${ }^{1}$, fundoplication ${ }^{2}$, laparoscopic

hysterectomy ${ }^{3}$ and liver resection ${ }^{4}$, it has also been used in thyroid surgery ${ }^{5}$ The ultrasound dissection using highfrequency mechanical energy for cutting and coagulating was established in the early1990s ${ }^{6}$. The dissection of tissue with ultrasound techniques is a further possibility that permits preparation and haemostasis at the same time. Reports on ultrasonically activated devices in thyroid surgery suggest a reduction of the operation time compared to the conventional technique ${ }^{7,8,9}$.

However the role of harmonic scalpel in salivary gland surgeries remains understudied. Review of literature yields on a few studies ${ }^{10,11,12,13}$.

\section{Materials and Methods}

This prospective study was conducted in the Postgraduate Department of Otorhinolaryngology \&Head and Neck Surgery of Government Medical College, Srinagar from April 2013 to October2015 after clearance from the ethical committee. Sufficient informed consent and agreement in accordance with the Helsinki declaration was obtained from the patients' in their own language.

Superficial parotidectomies were done using standard modified Blairs incision after which flaps were elevated to anterior border of masseter and facial nerve was routinely identified.

\section{Results}

Table 1: Average Operative time for superficial parotidecomies in the study

\begin{tabular}{|c|c|c|}
\hline Average (min) & Harmonic(min) & Conventional (min) \\
\hline $55.9(4.3)$ & $50.1(4.40)$ & $61.1(3.0)$ \\
\hline
\end{tabular}

Average operative time for superficial parotidectomies for harmonic group (50.10 min) was significantly shorter than Conventional group $(61.7 \mathrm{~min}), \mathrm{p}<.05$ as shown in the above table and figure below.

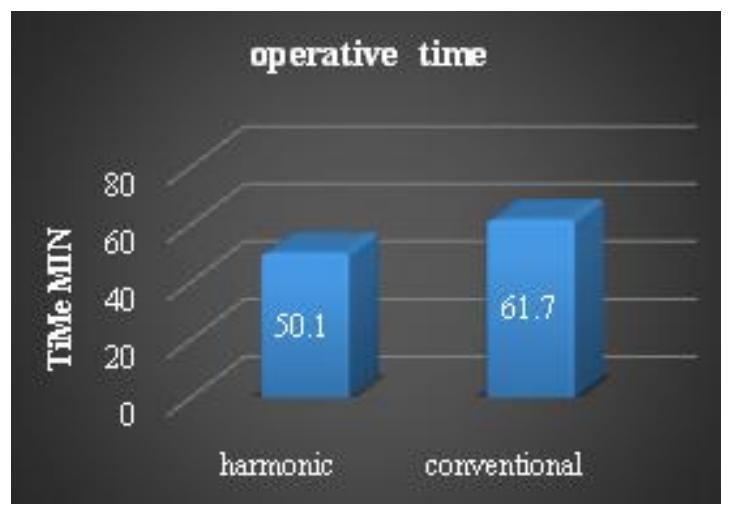

Table 2: Average Intraoperative Blood Loss in Superficial Parotidectomies

\begin{tabular}{|c|c|c|}
\hline Average $(\mathrm{ml})$ & Harmonic $(\mathrm{ml})$ & Conventional $(\mathrm{ml})$ \\
\hline $43.5(5.6)$ & $37.9(4.70)$ & $49.1(5.7)$ \\
\hline
\end{tabular}

Table 3: Postoperative Hospital stay for superficial parotidectomies shown in the following table.

\begin{tabular}{|c|c|c|}
\hline Average & Harmonic (DAYS) & Conventional (DAYS) \\
\hline 1.47 days(1.2) & $1.22(1.4)$ & $1.77(.90)$ \\
\hline
\end{tabular}

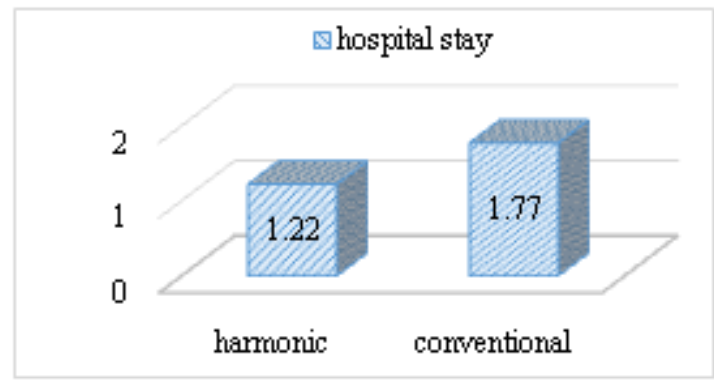

Figure 2

Volume 5 Issue 6, June 2016 www.ijsr.net 


\section{International Journal of Science and Research (IJSR) \\ ISSN (Online): 2319-7064}

Index Copernicus Value (2013): 6.14 | Impact Factor (2015): 6.391

Average hospital stay for superficial parotidectomy patients was significantly shorter in Harmonic group (1.22 days) than in Conventional group (1.77days), with a $\mathrm{p}$ value <.05.

Table 4: Postoperative pain using visual analogue scale for superficial parotidectomies showed in following table

\begin{tabular}{|c|c|c|c|}
\hline Time in Hrs & $\begin{array}{c}\text { Harmonic } \\
\text { Group }\end{array}$ & $\begin{array}{c}\text { Conventional } \\
\text { Group }\end{array}$ & Average \\
\hline 6 & $5.9(2.5)$ & $6.9(2.1)$ & $6.7(1.7)$ \\
\hline 24 & $2.8(.9)$ & $4.9(1.4)$ & $3.7(1.2)$ \\
\hline
\end{tabular}

Average postoperative pain in patients undergoing superficial parotidectomy was less in harmonic group than conventional group but statistically significant only at $24 \mathrm{hrs}$ shown in figure below.

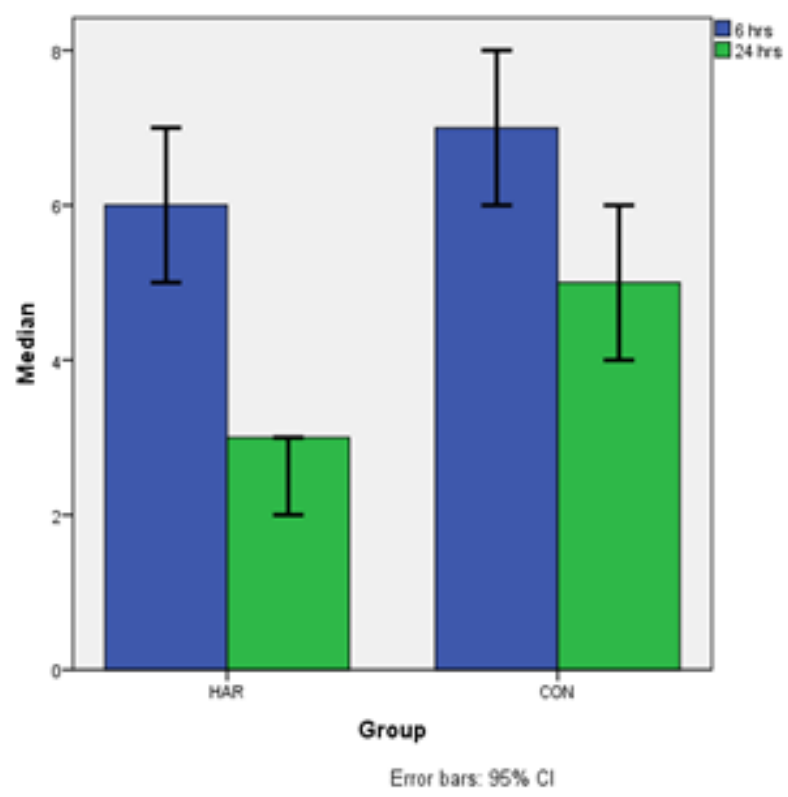

\section{Discussion}

The present study included 30 superficial parotidectomies 15 of which were done by harmonic scalpel and 15 by conventional method. Sex distribution revealed 16 male patients and 14 female patients. Analysis of data revealed average operative time for superficial parotidectomies for harmonic group (50.10 min) was significantly shorter than Conventional group $(61.7 \mathrm{~min}), \mathrm{p}$ value<.05.Average intraoperative blood loss in superficial parotidectomy patients was significantly less for harmonic group $(37.9 \mathrm{ml})$ than conventional group $(49.1 \mathrm{ml})$, p value $<05$.

Furthermore, average hospital stay for superficial parotidectomy patients was significantly shorter in Harmonic group (1.22 days) than in Conventional group (1.77days), with a $\mathrm{p}$ value $<.05$.

Average postoperative pain in patients undergoing superficial parotidectomies less in Harmonic group than conventional group but statistically significant only at 24 HRS.

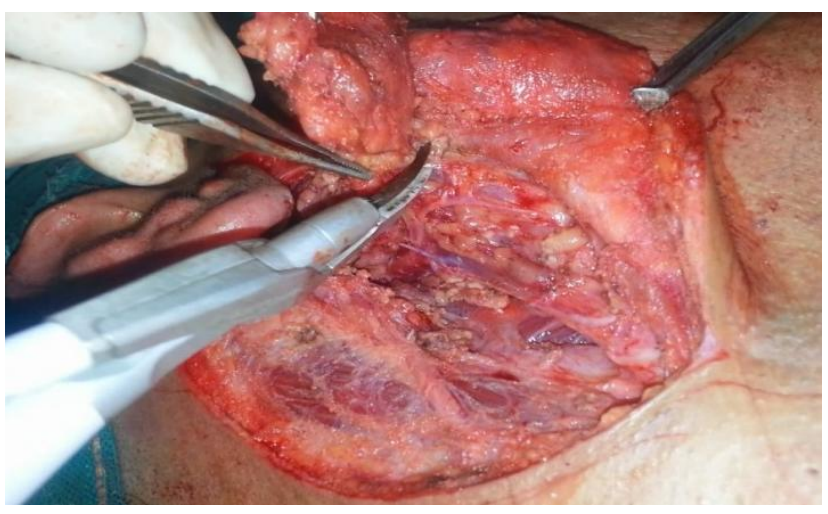

Right superficial parotidectomy being operated using harmonic scalpel being shown in the above photograph.

Jackson ${ }^{11} \mathrm{LL}$ et al studied forty-four patients underwent harmonic scalpel parotidectomy and 41 patients underwent conventional cold knife parotidectomy (control group). Use of the harmonic scalpel was associated with a significant reduction in intraoperative blood loss $(38.0+/-3.6 \mathrm{~mL}$ vs $66.0+/-10.8 \mathrm{~mL}$ for controls, $\mathrm{P}<0.05)$ and duration of drainage $(31.80+/-2.4$ h vs. $39.29+/-2.21$ h for controls, $\mathrm{P}$ $<0.05)$. Use of the harmonic scalpel in superficial parotidectomy $(n=35)$ compared to controls $(n=37)$ was associated with a significant reduction in intraoperative blood loss $(38.0+/-4.23 \mathrm{~mL}$ vs. $68.0+/-12.0 \mathrm{~mL}, \mathrm{P}<0.05)$. Blankenship ${ }^{12}$ et al in their study had forty-two patients who were eligible for inclusion. Nineteen patients underwent Harmonic Scalpel parotidectomy (HS) and 21 patients underwent conventional parotidectomy (control group). There were no significant differences between the 2 groups with respect to demographic data, pathology, or tumor size. Use of the Harmonic Scalpel was associated with a significant reduction in length of surgery $(167.5+/-42.6 \mathrm{~min}$ vs. $195.5+/-37.4 \mathrm{~min}$ for controls, $\mathrm{P}=0.03$ ) and intraoperative blood loss $(37.5+/-25.8 \mathrm{~mL}$ vs. $60.0+/-37.1$ $\mathrm{mL}$ for controls, $\mathrm{P}=0.03)$.A. Deganello ${ }^{13}$ et al in their study found the admission time was significantly shorter in the HS group than the CI group $(3.9 \pm 1.2$ days and $4.7 \pm 1.4$ days, respectively, $\mathrm{p}<0.01$

The results from the present study are in accordance with the literature with regard to less operative time, intraoperative blood loss and hospital stay but actual values differ most likely due to local practice and technique.

\section{References}

[1] Tebala GD. Three-port laparoscopic cholecystectomy by harmonic dissection without cystic duct and artery clipping. Am J Surg 2006; 191:718-20.

[2] Underwood RA, Dunnegan DL, Soper NJ. Prospective, randomized trial of bipolar electrosurgery vs ultrasonic coagulation for division of short gastric vessels during laparoscopic Nissen fundoplication. SurgEndosc 1999; 13: $763-8$

[3] Nezhat F, Mahdavi A, Nagarsheth NP. Total laparoscopic radical hysterectomy and pelvic lymphadenectomy using harmonic shears. J Minim Invasive Gynecol 2006; 13:20-5

[4] Wrightson WR, Edwards MJ, McMasters KM. The role of the ultrasonically activated shears and vascular

\section{Volume 5 Issue 6, June 2016}




\section{International Journal of Science and Research (IJSR) \\ ISSN (Online): 2319-7064}

Index Copernicus Value (2013): 6.14 | Impact Factor (2015): 6.391

cutting stapler in hepatic resection. Am Surg 2000; 66:1037-40.

[5] Siperstein AE, Berber E, Morkoyun E. The use of the harmonic scalpel vs conventional knot tying for vessel ligation in thyroid surgery. Arch Surg 2002; 137:13742.

[6] Amaral JF: The experimental development of an ultrasonically activated scalpel for laparoscopic use. SurgLaparoscEndosc 1994; 4:92-99

[7] Meurisse,Dralle H, Sekulla C, Haerting J, TimmermannW, Neumann HJ, Kruse E, GrondS,Mühlig HP, Richter C, Voss J, ThomuschO,Lippert H, Gastinger I, Brauckhoff M, GimmO: Risk factors of paralysis and functional outcome after recurrent laryngeal nerve monitoring in thyroid surgery. Surgery 2004; 136: 1310-1322

[8] Voutilainen PE, Haglund CH: Ultrasonically activated shears in thyroidectomies: a randomizedtrial. Ann Surg 2000; 231: 322-328

[9] Siewert JR, Rothmund M, Schumpelick V (eds): EndokrineChirurgie, ed 2. Praxis der Viszeralchirurgie. Berlin, Springer, 2007

[10] Medical College of Georgia; Special scalpel reduces blood loss, facial nerve trauma in salivary surgery.

[11] Jackson LL1, Gourin CG, Thomas DS, Porubsky ES, Klippert FN, Terris DJ. Use of the harmonic scalpel in superficial and total parotidectomy for benign and malignant disease. Laryngoscope. 2005 Jun; 115(6):1070-3.

[12] Blankenship DR1, Gourin CG, Porubsky EA, Porubsky ES, Klippert FN, Whitaker EG, Terris DJ. Harmonic Scalpel versus cold knife dissection in superficial parotidectomy. Otolaryngol Head Neck Surg. 2004 Oct; 131(4):397-400.

[13] Deganello, G. Meccariello, M. Busoni, G. Parrinello, R. Bertolai and O. Gallo.Dissectionwith harmonic scalpel versus cold instruments in parotid surgery B-ENT, 2014, 10, 175-178. 